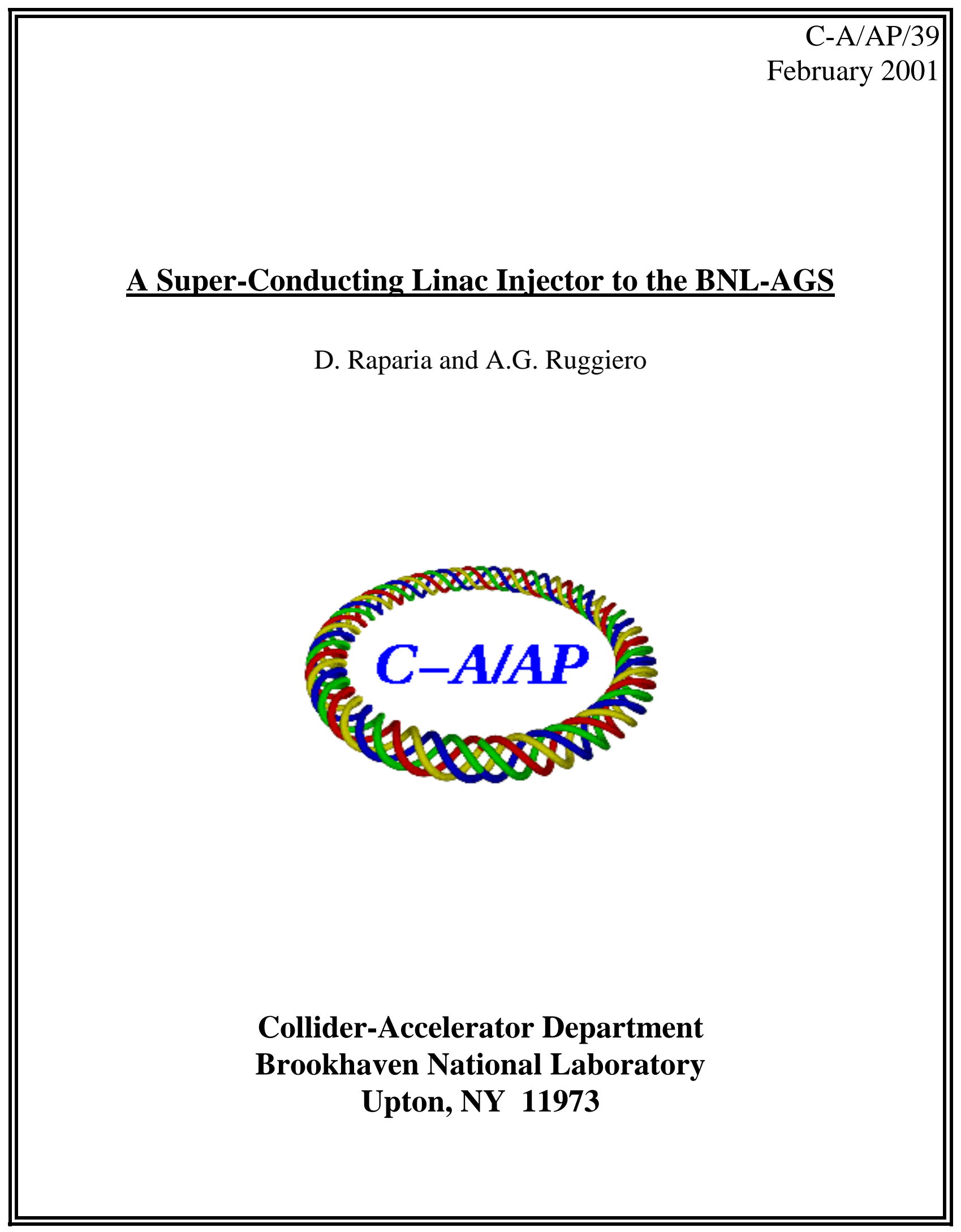




\title{
A Super-Conducting Linac Injector to the BNL-AGS*
}

\author{
D. Raparia and A.G. Ruggiero \\ Brookhaven National Laboratory, PO BOX 5000, Upton; NY 11973 \\ July 31,2000
}

\begin{abstract}
This paper reports on the feasibility study of a proton Super-Conducting Linac as a new " injector to the Alternating Gradient Synchrotron (AGS) of the Brookhaven National Laboratory (BNL). The Linac beam energy is in the range of 1.5 to $2.4 \mathrm{GeV}$. The beam intensity is adjusted to provide an average beam power of $4 \mathrm{MW}$ at the top energy of 24 $\mathrm{GeV}$. The repetition rate of the Linac-AGS facility is 5 beam pulses per second:
\end{abstract}

\section{Introduction}

It has been proposed to upgrade the Alternating Gradient Synchrotron (AGS) accelerator complex to provide an average proton beam power of $4 \mathrm{MW}$ at the energy of $24 \mathrm{GeV}$. The facility can be used either as a proton driver for the production of intense muon and neutrino beams, or/and as a pulsed high-energy spallation neutron source. The upgrade: requires operation of the accelerator at the rate of five cycles per second; and a new.... injector for an increase of the AGS beam intensity by a factor of three.

In a separate technical report: [1] we have described the methods and the requirements to operate the Brookhaven AGS accelerator facility at the rate of 5 proton ". beam pulses per second. The major requirement is an extensive addition and modification of the present power supply system. Also other components, notably the accelerating rf cavity system, will have to be substantially modified to allow a six-fold increase of the acceleration rate. At the same time, a new injector to the AGS, capable to operate at the rate of 5 beam pulses per second; and to provide a three-fold increase of the present beam intensity; is required: The present injector made of the $200-\mathrm{MeV}$ Linac and of the 1.5-GeV AGS-Booster will not be able to fulfill the goals of the upgrade.

The proposed new injector, described in this technical report, is a $1.5-2.4 \mathrm{GeV}$ Super-Conducting Linac (SCL) with an average output beam power of $250-400 \mathrm{~kW}$. The largest energy is determined by the capability to limit beam losses due to stripping of the negative ions that are used for multi-turn injection into the synchrotron. The highenergy case is to be preferred if one wants to reduce the effects of space charge; andito * accommodate adequately the beam transverse size in the aperture of the accelerator. The duty cycle is about a half percent. The operation frequency has been chosen to be 805 MHz.

The paper describes the preliminary design of the Super-Conducting Linac. It is composed of three parts; a front end; that is a $60-\mathrm{mA}$ negative-ion source, followed by a 5-MeV RFQ, a room temperature Drift -Tube Linac (DTL) that accelerates protons to $150 \mathrm{MeV}$, and the Super-Conducting Linac proper. (SCL): This in turn is made of four

- Work performed under the auspices of the US Department of Energy. 
sections, each with its own energy range; and different cavity-cryostat arrangement. The four sections are labeled: Low-Energy (LE), Mediüm Low-Energy (MLE), Medium. High-Energy (MHE), and High-Energy (HE).

\section{The New Injector}

The two different Linac energy cases are compared in Table 1.:AGS performance during multi-turn injection is also summarized in the same Table. Both cases correspond to the same average beam current of $0.17 \mathrm{~mA}$, that yields the same average beam power of: $4 \mathrm{MW}$ at the top energy of $24 \mathrm{GeV}$. The repetition rate of 5 beam pulses per second is assumed in both cases; that gives the same intensity of $2.1 \times 10^{14}$ protons accelerated per AGS cycle; that is a factor of 3 higher then the intensity routinely obtained with the present injector. At the end of injection, that takes about 317-330 turns, the space-charge tune depression is $\Delta v=0.4$ at the energy of $1.5 \mathrm{GeV}$, and $\Delta v=0.2$ at $2.4 \mathrm{GeV}$, assuming. a bunching factor (the ratio of beam peak current to average current), during the early part of the acceleration cycle, of 4 . Also, with the same normalized beam emittance of $250 \pi \mathrm{mm}$-mrad, the actual beam emittance is smaller at $2.4 \mathrm{GeV}, \varepsilon=73 \pi \mathrm{mm}$-mrad, versus $104 \pi \mathrm{mm}$-mrad at $1.5 \mathrm{GeV}$.Obviously, the effective acceptance of the AGS at injection is to be larger than these beam emittance values.

The front-end of the Linac is made of an ion source operating with a $1 \%$ duty cycle at the repetition rate of 5 pulses per second. The beam current within a pulse is $60 \mathrm{~mA}$ of negative-hydrogen ions. The ion source seats on a platform at $35-60 \mathrm{kVolt}$; and is followed by a $5-\mathrm{MeV}$ RFQ that works at $402.5 \mathrm{MHz}$. The beam is pre-chopped by a chopper located between the ion source and the $\mathrm{RFQ}$. The beam chopping extends over $75 \%$ of the beam length, at a frequency matching the accelerating rf $(4: 1-4.28 \mathrm{MHz})$ at injection into the AGS. Moreover, the transmission efficiency through the RFQ is taken. conservatively to be $80 \%$, so that the average current of the beam pulse in the Linac, where we assume no further beam loss, is $36 \mathrm{~mA}$.

The combination of the chopper and of the RFQ pre-bunches the beam with a sufficiently small longitudinal extension so that each of the beam bunches at $402.5 \mathrm{MHz}$ can be entirely fitted in the accelerating if buckets of the following DTL that operates at either 402.5 or $805 \mathrm{MHz}$. The DTL is a room temperature conventional Linac that is not discussed here, except noting that the beam energy in exit is $150 \mathrm{MeV}$.

\section{The Super-Conducting Linac (SCL)}

The Super-Conducting Linac (SCL) accelerates the proton beam from $150 \mathrm{MeV}$ to $1: 5$ or $2.4 \mathrm{GeV}$. The configuration and the design procedure of the SCL is described in detailin [2]. It is typically a sequence of a number of identical periods as shown in Figure 1. Each period is made of a cryo-module of length $L_{\text {cryo }}$ and of an insertion of length $L_{\text {ins }}^{\ldots}$. The insertion is needed for the placement of focusing quadrupoles, vacuum pumps, steering magnets; beam diagnostic devices, bellows and flanges. It can be either at room: temperature or in a cryostat as: well. Here we assume that the insertions are at room: temperature. The cryo-module includes $M$ identical cavities, each of $N$ identical cells, and 
each having a length $N L_{\text {cell }}$, where $L_{\text {cell }}$ is the length of a cell. Cavities are separated from each other by a drift space $d$. An extra drift of length $L_{\mathrm{w}}$ may be added internally on both sides of the cryo-module to provide a transition between cold and warm regions. Thus,

$$
L_{\text {cryo }}=M N L_{\text {cell }}+(M-1) d \cdots+2 L_{\mathrm{w}}
$$

Table 1. Injector and AGS Parameters for the Upgrade

\begin{tabular}{|l|r|r|}
\hline Linac Average Power, MW & 0.25 & 0.40 \\
\hline \hline Kinetic Energy, GeV & 1.5 & 2.4 \\
\hline$\beta$ & 0.9230 & 0.9597 \\
\hline Momentum, GeV/c & 2.2505 & 3.2037 \\
\hline Magnetic Rigidity, T-m & 7.5068 & 10.6862 \\
\hline Repetition Rate, $\mathrm{Hz}$ & 5 & 5 \\
\hline Average Current, $\mathrm{mA}$ & 0.1667 & 0.1667 \\
\hline Tot. Number of Protons & $2.0833 \times 10^{14}$ & $2.0833 \times 10^{14}$ \\
\hline AGS Circumference, $\mathrm{m}$ & 807.12 & 807.12 \\
\hline Revol. Frequency, MHz & 0.3428 & 0.3565 \\
\hline Revolution Period, $\mu \mathrm{s}$ & 2.9169 & 2.8053 \\
\hline Bending Radius & 79.832 & 79.832 \\
\hline Injection Field & 0.9403 & 1.3386 \\
\hline Ion Source Current, $\mathrm{mA}$ & 60 & 60 \\
\hline RFQ Transmission, \% & 80 & 80 \\
\hline Chopping Ratio, \% & 75 & 75 \\
\hline Peak Current, $\mathrm{mA}$ & 48 & 48 \\
\hline Average Current, $\mathrm{mA}$ & 36 & 36 \\
\hline Protons per Turn & $6.563 \times 10^{11}$ & $6.312 \times 10^{11}$ \\
\hline Number of injected Turns & 317 & 330 \\
\hline Beam Pulse Length, ms & 0.9259 & 0.9259 \\
\hline Duty Cycle, \% & 0.4630 & 0.4630 \\
\hline Bunching Factor & 4 & 4 \\
\hline Norm. Emitt., $\pi$ mm-mrad & 250 & 250 \\
\hline Emittance, $\pi$ mm-mrad & 104. & 73. \\
\hline Space- Charge $\Delta v$ & 0.41 & 0.21 \\
\hline
\end{tabular}

There are two symmetric intervals: a minor one, between the two middle points $\mathrm{A}$ and B, as shown in Figure 1,"that is the interval of a cavity of length $N L_{\text {cell }}+d$; and a major one, between the two middle points $C$ and $D$, that defines the range of a period of total length $L_{\text {cryo }}+L_{\text {ins }}$. Thus, the topology of a period can be represented as a drift of length $g$, followed by $M$ cavity intervals, and a final drift of length $g$, where

$$
g=L_{\mathrm{w}}+\left(L_{\text {ins }}-d\right) / 2
$$

The choice of cryo-modules with identical geometry, and with the same cavity/cell configuration, is economical and convenient for construction. But there is, 
nonetheless, a penalty due to the reduced transit-time-factors when a particle crosses cavity cells, with length adjusted to a common central value $\beta_{0}$ that does not correspond to the particle instantaneous velocity: To minimize this affect the SCLis divided in four sections, each designed around a different central value $\beta_{0}$, and; therefore, with different cavity/cell configuration. The cell length in a section is fixed to be

$L_{\text {cell }}=\lambda \beta_{0} / 2$

where $\lambda$ is the rf wavelength. We:assume the same operating frequency of $805 \mathrm{MHz}$ for the entire $\mathrm{SCL}$, so that $\lambda=37.24 \mathrm{~cm}$. The major parameters of the four sections of the SCL are given in Tables 2 and 3 . The cost estimate (with no contingency) for each section of the SCL has been made assuming the cost and rf parameters shown in Table 4. The total expected cost is around $300 \mathrm{M} \$$, including also the front-end and the roomtemperature DTL.
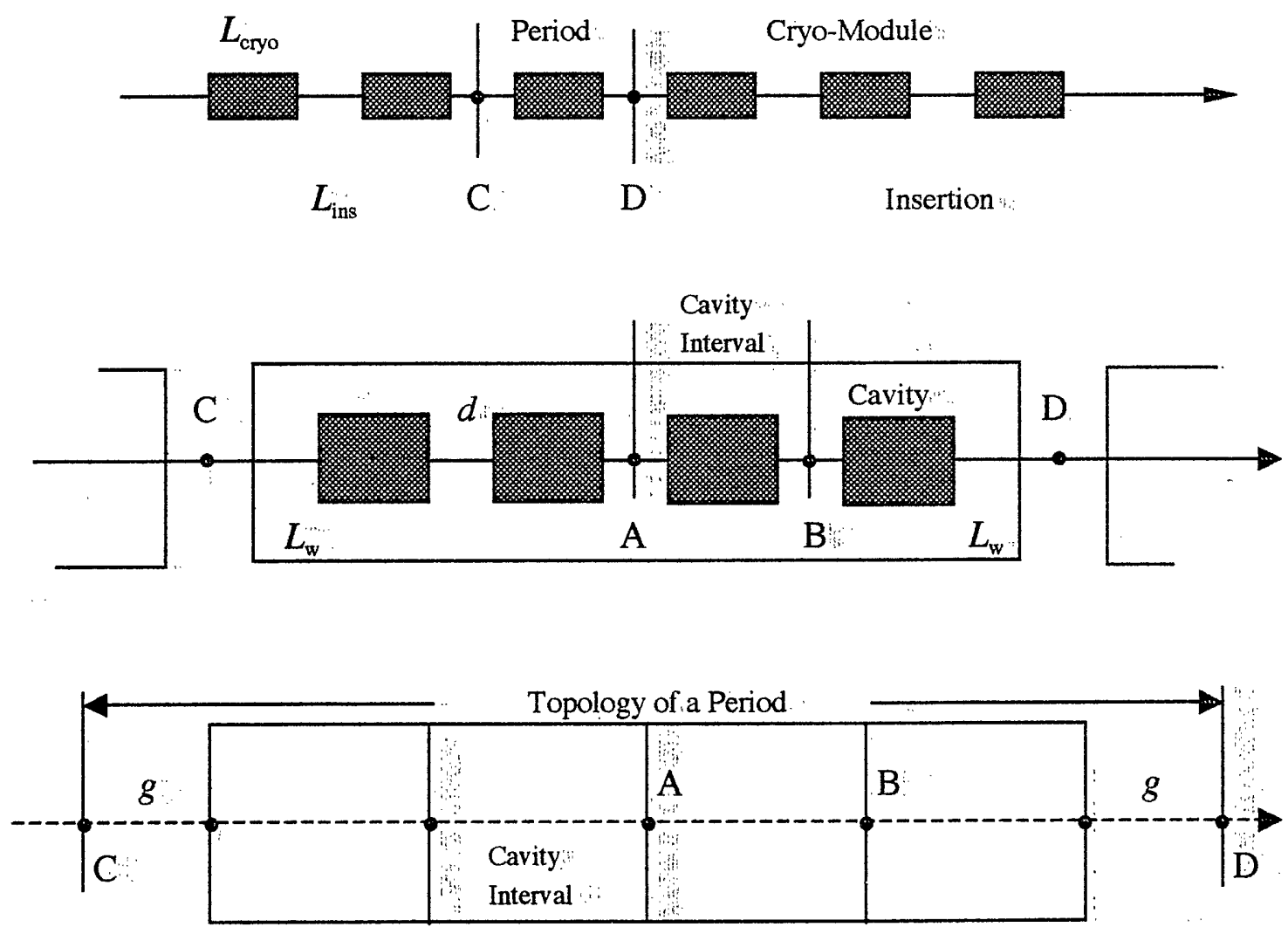

Figure 1. Configuration of a Proton Super-Conducting Linear Accelerator

The length of the Linac depends on the average accelerating gradient. The local gradient has a maximum value that is limited by three causes: (1) The surface field limit at the frequency of the $805 \mathrm{MHz}$ is $26 \mathrm{MV} / \mathrm{m}$. For a realistic cavity shape, we set a limit: of a $13 \mathrm{MV} / \mathrm{m}$ on the axial electric field: (2) There is a limit on the power provided by $\mathrm{rf}$. couplers that we take here not to exceed $400 \mathrm{~kW}$, including a contingency of $50 \%$ to 
avoid saturation effects. (3) To make the longitudinal motion stable; we can only apply an energy gain per cryo-module that is a relatively small fraction of the beam energy in exit of the cryo-module. The conditions for stability of motion have been derived in [2].

The proposed mode of operation is to operate each section of the SCL with the same rf input power per cryo-module. This will result to some variation of the actual. axial field from one cryo-module to the next. If one requires also a constant value of the axial field, this may be obtained by adjusting locally the value of the rf phase The number of cells and cavities varies from insertion to insertion. The number of couplers varies for 1 to 2 . The total length of the injector including the front-end and the:DTL is expected to be about 500 meters. The location of the new injector is shown in Figure 2 . It runs at an angle of about $30^{\circ}$ on the side of the present $200-\mathrm{MeV}$ Linac.

It is proposed to build the entire SCL in two stages. During the first stage the final : energy if $1.5 \mathrm{GeV}$, and the Linac is made of the three first sections. In a second stage the High-Energy section is added for the final energy of $2.4 \mathrm{GeV}$, if indeed this should result to be necessary.

Table 2. General Parameters of the SCL

\begin{tabular}{|l|r|r|r|r|}
\hline Linac Section & \multicolumn{1}{|c|}{ LE } & \multicolumn{1}{c|}{ MLE } & MHE & HE \\
\hline \hline Average Beam Power, $\mathrm{kW}$ & 50 & 133 & 250 & 400 \\
\hline Average Beam Current; $\mathrm{mA}$ & 0.167 & 0.167 & 0.167 & 0.167 \\
\hline Initial Kinetic Energy, GeV & 0.150 & 0.300 & 0.800 & 1.500 \\
\hline Final Kinetic Energy, GeV & 0.300 & 0.800 & 1.500 & 2.400 \\
\hline Frequency, MHz & 805 & 805 & 805 & 805 \\
\hline No. of Protons / Bunch $\times 10^{8}$ & 3.73 & 3.73 & 3.73 & 3.73 \\
\hline Temperature, ${ }^{\circ} \mathrm{K}$ & 2.0 & 2.0 & 2.0 & 2.0 \\
\hline \hline Cells / Cavity & 4 & 4 & 4 & 4 \\
\hline Cavities / Cryo-Module & 4 & 8 & 8 & 8 \\
\hline Cavity Separation, cm & 32 & 32 & 32 & 32 \\
\hline Cold-Warm Transition, cm & 30 & 30 & 30 & 30 \\
\hline Cavity Internal Diameter, cm & 10 & 10 & 10 & 10 \\
\hline Length of Warm Insertion, m & 1.079 & 11079 & 1.079 & 1.079 \\
\hline \hline Accelerating Gradient, MeV/m & 12.2 & 11.9 & 12.9 & 12.4 \\
\hline Cavities / Klystron & 4 & 8 & 4 & 4 \\
\hline No. of rf Couplers / Cavity & 1 & 1 & 2 & 2 \\
\hline \hline Rf Phase Angle & $30^{\circ}$ & $30^{\circ}$ & $30^{\circ}$ & $30^{\circ}$ \\
\hline Method for Transverse Focussing & FODO & FODO & FODO & FODO \\
\hline Betatron Phase Advance / FODO cell & $90^{\circ}$ & $90^{\circ}$ & $90^{\circ}$ & $90^{\circ}$ \\
\hline \hline Norm. rms Emittance, $\pi$ mm-mrad & 0.30 & 0.30 & 0.30 & 0.30 \\
\hline Rms Bunch Area, $\pi{ }^{\circ}$ MeV & 0.5 & 0.5 & 0.5 & 0.5 \\
\hline
\end{tabular}

Negative ion stripping during transport down the SCL has been found to be very negligible. But the final $30^{\circ}$ bend, before injection into the AGS, could be of a concern [3]. To control the rate of beam loss by stripping to a $10^{-4}$ level, the bending field should not exceed $2.6 \mathrm{kGauss}$ over a total integrated bending length of $15 \mathrm{~m}$, in the case of the : 
lower beam energy of $1.5 \mathrm{GeV}$. At the energy of $2.4 \mathrm{GeV}$ the bending field is 1.9 $\mathrm{kGauss}$, and the integrated bending length is about $30 \mathrm{~m}$.

Table:3. Summary of the SCL Design

\begin{tabular}{|c|c|c|c|c|}
\hline Linac Section & LE. & MLE & MHE & $\mathrm{HE}$ \\
\hline Energy: in - out, $\mathrm{GeV}$ & $.15-0.30$ & $0.30-0.80$ & $0.80-1.50$ & $1.50-2.40$ \\
\hline Velocity, $\beta$ : in & 0.5066 & 0.6526 & 0.8418 & 0.9230 \\
\hline out & 0.6526 & 0.8418 & 0.9230 & 0.9597 \\
\hline Cell Reference $\beta_{0}$ & 0.530 & 0.680 & $\mathbf{0 . 8 5 0}$ & 0.935 \\
\hline Cell Length, $\mathrm{cm}$. & 9.87 & 12.66 & 15.83 & 17.41 \\
\hline Total No. of Periods & 9 & 12 & 13. & 15 \\
\hline Length of a period, $m$ & 4.218 & 7.971 & 8.984 & 9.490 \\
\hline FODO-Cell ampl. func, $\beta_{0}, \mathrm{~m}$ & 14.40 . & 27.21 & 30.67 & 32.40 \\
\hline Total Length, $m$ & $37: 96$ & 95.65 & 116.79 & $142: 35$ \\
\hline Coupler if Power, $\mathrm{kW}(*)$ & 300 & 375 & 255 & 270 \\
\hline Energy Gain/Period, $\mathrm{MeV}$ & 16.67 & 41.67. & 56.67. & 60.00 \\
\hline Total No. of Klystrons & 9 & 12 & 26 & 30 \\
\hline Klystron Power, kW (*): & 1200 & 3000 & 2040 & 2160 \\
\hline $\mathrm{Z}_{0} \mathrm{~T}_{0}^{2} ; \mathrm{ohm} / \mathrm{m}$ & 271.8 & 447.4 & 699.0 & 845.8 \\
\hline $\mathrm{Q}_{0} \times 10^{9}$ & 5.5 & 7.0 & 8.7 & 9.6 \\
\hline Ave: Dissipated Power, $\mathrm{kW}$ & 0.009 & 0.012 & 0.009 & 0.008 \\
\hline Ave. HOM-Power, $\mathrm{kW}$ & 0.0016 & 0.0042 & 0.0046 & 0.0053 \\
\hline Ave. Cryogenic Power, $\mathrm{kW}$ & 0.152 & 0.430 & 0.527 & 0.644 \\
\hline Ave. Beam Power, MW & 0.025 & 0.083 & 0.117 & 0.150 \\
\hline Total Ave. rf Power, MW ( & 0.050 & 0.149 & 0.197 & 0.248 \\
\hline Ave. AC Power for rf, MW $(*)$ & $0: 110$ & 0.331 & 0.438 & 0.552 \\
\hline Ave. AC Power for Cryo., & 0.038 & 0.107 & 0.132 & 0.161 \\
\hline Total Ave. AC Power, $M$ & 0.148 & 0.439 & 0.570 & 0.713 \\
\hline Efficiency, \% (*) & 16.9 & 19.0 & 20.5 & 21.0 \\
\hline $\begin{array}{l}\text { Capital Cost'00 M\$: } \\
\text { Rf Klystron }(*)\end{array}$ & 0.124 & 0.373 & 0.493 & 0.621 \\
\hline El & 0.021 & $0: 061$ & 0.080 & 0.100 \\
\hline $\operatorname{Re}$ & 0.303 & $0: 860$ & 1.055 & 1.288 \\
\hline Struc & 1.619 & 2.104 & 2.266 & 2.590 \\
\hline Cold Structure & 14.126 & 41.351 & 51.381 & 63.085 \\
\hline Tunnel & 3.904 & 9.673 & 11.787 & 14.343 \\
\hline Total Cost, ' $00 \mathrm{M} \$\left({ }^{*}\right)$ & 20.096 & 54.422 & 67.061 & 82.027 \\
\hline Operation Cost, ${ }^{\prime} 00 \mathrm{M} \$ / \mathbf{y}\left({ }^{*}\right)$ & 0.049 & 0.144 & 0.187 & 0.234 \\
\hline
\end{tabular}

$\left({ }^{*}\right)$ Including $50 \%$ if power contingency:

A Super-Conducting Linac is most advantageous for a continuous mode of operation (CW). There are two problems in the case of the pulsed-mode of operation. First, the pulsed thermal cycle introduces Lorentz forces that deform the cavity cells out of . 
resonance. This can be controlled with a thick cavity wall strengthened to the outside by supports. Second, there is an appreciable period of time to fill the cavities with rf power before the maximum gradient is reached [2]. During the filling time, extra power is dissipated also before the beam is injected into the Linac. The extra amount of power required is the ratio of the filling time to the beam pulse length. The filling time is $0.30 \mathrm{~ms}$ for the LE section, $0.18 \mathrm{~ms}$ for the MLE section, $0.12 \mathrm{~ms}$ for the MHE section, and 0.10 $\mathrm{ms}$ for the HE section. In comparison, the beam pulse length is $0.93 \mathrm{~ms}$.

Table 4. Cost ('00 \$) and Other Parameters

\begin{tabular}{|l|r|l|}
\hline AC-to-rf Efficiency & 0.45 & For pulsed mode \\
\hline Cryogenic Efficiency & 0.004 & At $2.0^{\circ} \mathrm{K}$ \\
\hline Electricity Cost & 0.05 & $\$ / \mathrm{kWh}$ \\
\hline Linac Availability & 75 & $\%$ of yearly time \\
\hline Normal Conducting Cost & 150 & $\mathrm{k} \$ / \mathrm{m}$ \\
\hline Superconducting Cost & 500 & $\mathrm{k} \$ / \mathrm{m}$ \\
\hline Tunnel Cost & 100 & $\mathrm{k} \$ / \mathrm{m}$ \\
\hline Cost of Klystron & 2.50 & $\$ / \mathrm{W}$ of rf Power \\
\hline Cost of Refrigeration Plant & 2 & $\mathrm{k} \$ / \mathrm{W}$ of Power @ $2.0^{\circ} \mathrm{K}$ \\
\hline Cost of Electrical Distribution & 0.14 & $\$ / \mathrm{W}$ of AC Power \\
\hline
\end{tabular}

A program [4] was written in Visual Basic included with the MS Excel application, to calculate the beam and if dynamics during acceleration in each of the four sections of the SCL. The results are displayed in Figures 3 to 14 .

\section{References}

[1] I. Marneris and A.G. Ruggiero, ":Running the AGS MMPS at $5 \mathrm{~Hz} ; 24 \mathrm{GeV}$ ". BNL-Internal Report C-A/AP/12. January 21,2000.

[2] A. G. Ruggiero, "Design Considerations on a Proton Superconducting Linac": BNL-Internal Report 62312. Aügust 1995.

[3] A. G. Ruggiero, "Negative-Ion Injection by Charge Exchange at $2.4 \mathrm{GeV}$ ". BNL-Internal Report 62310. September 1995.

[4] The program is available by making request to one of the Authors. 


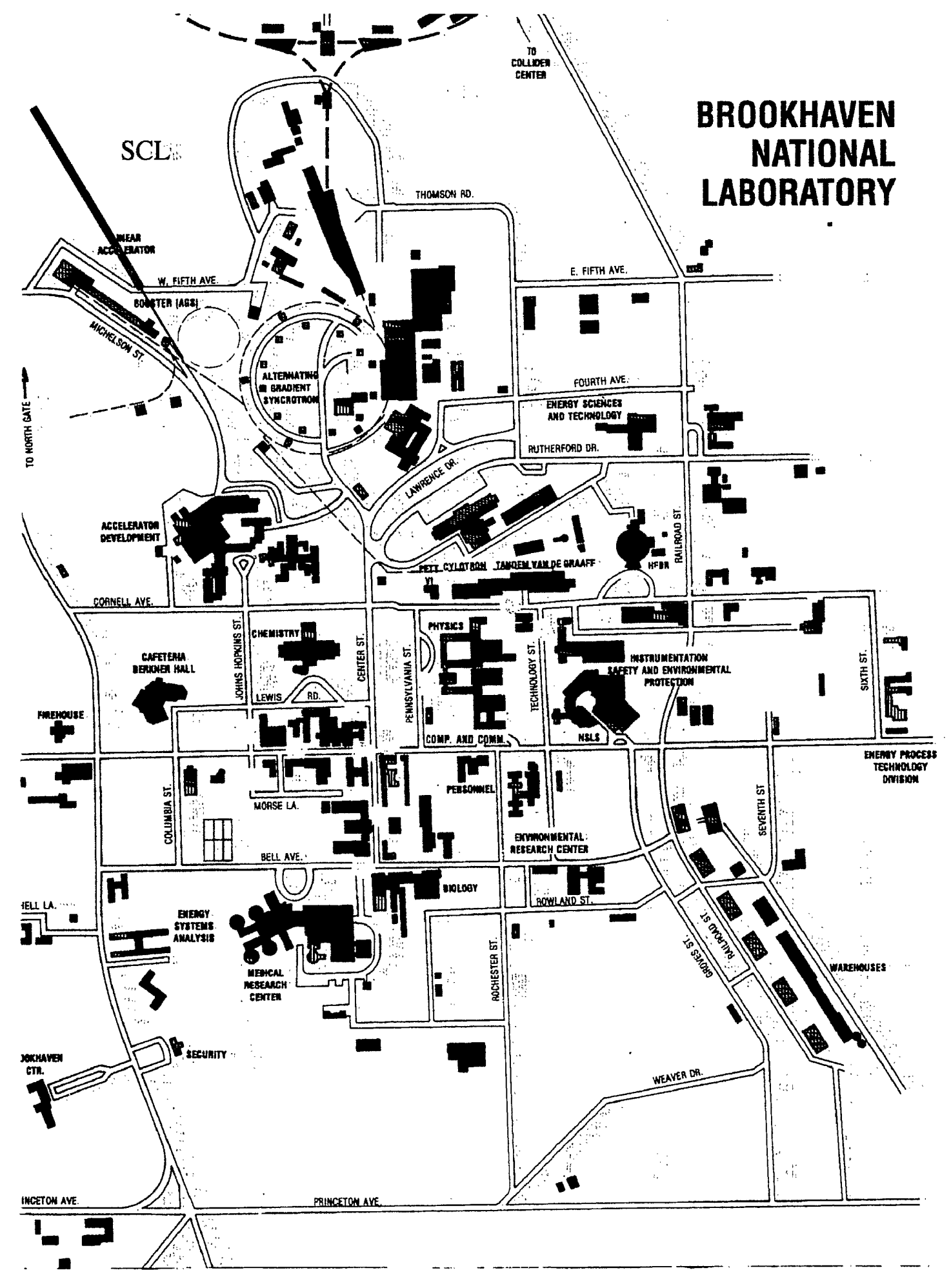

Figure 2. BNL Site with the SCL. Injector and the AGS Facility 

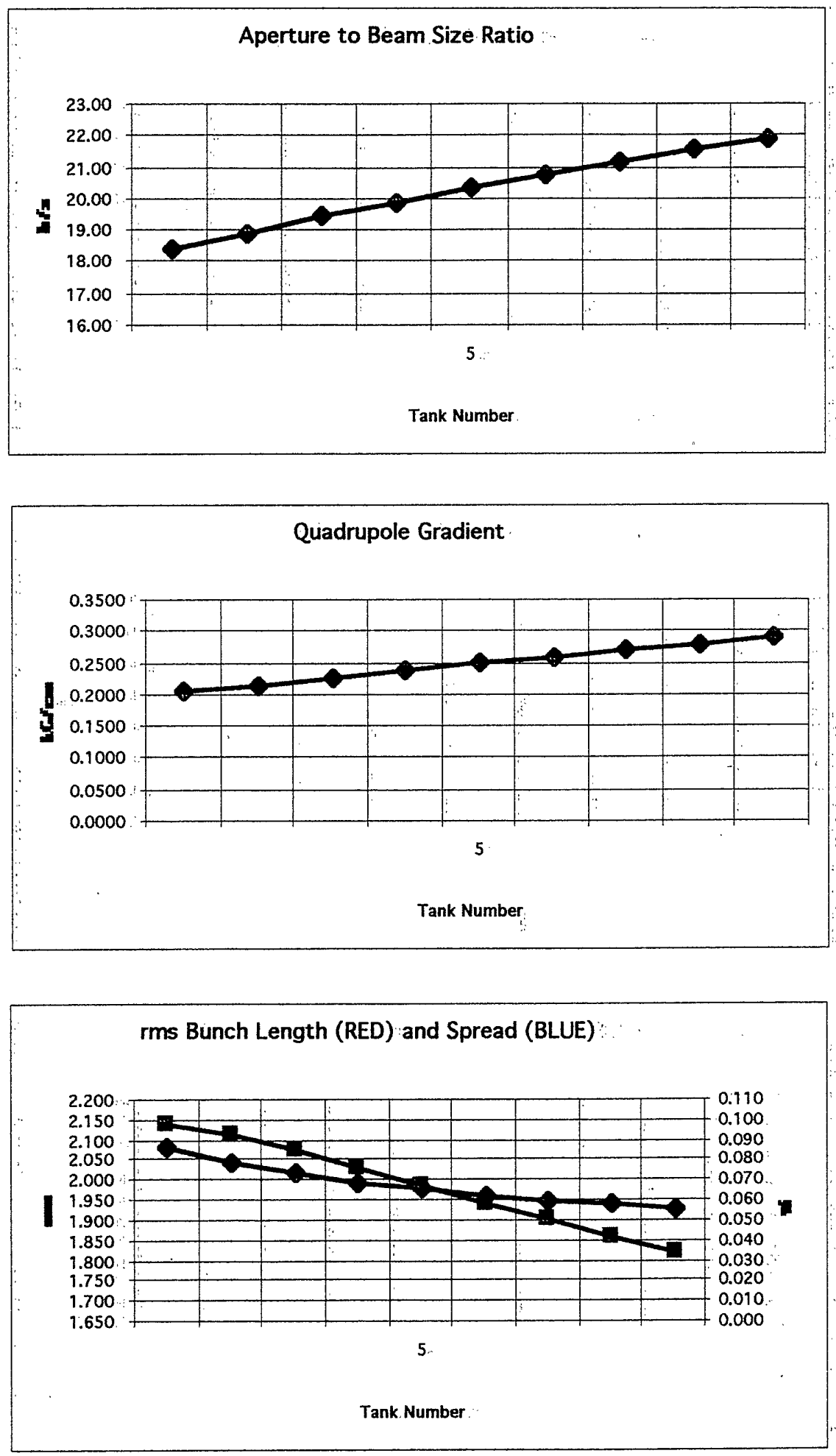

Figure 3. Plots (1) of Behavior vs: period (tank) number of LE Section. 

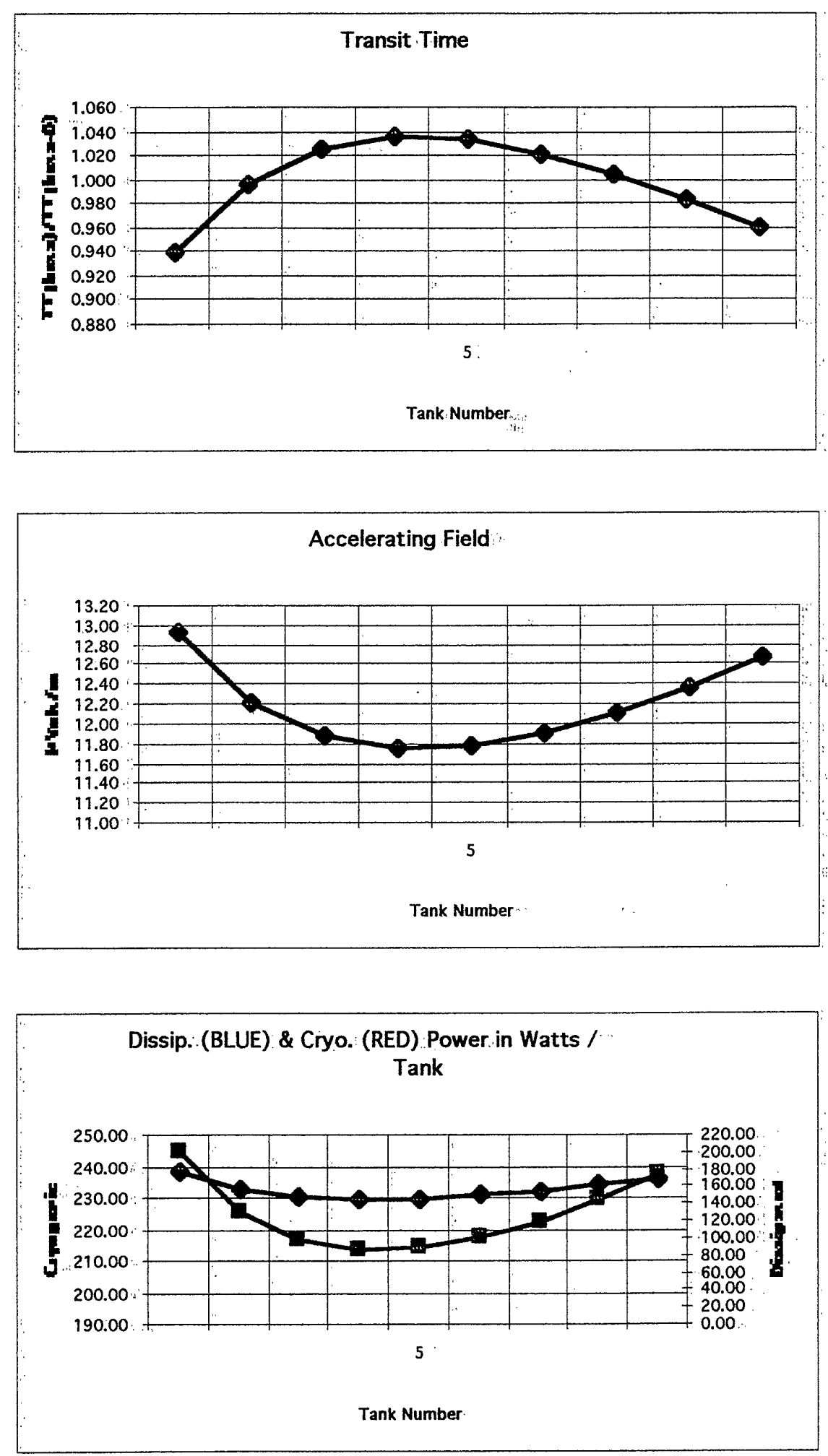

Figure 4. Plots (2) of Behavior vs. period (tank) number of LE Section. 

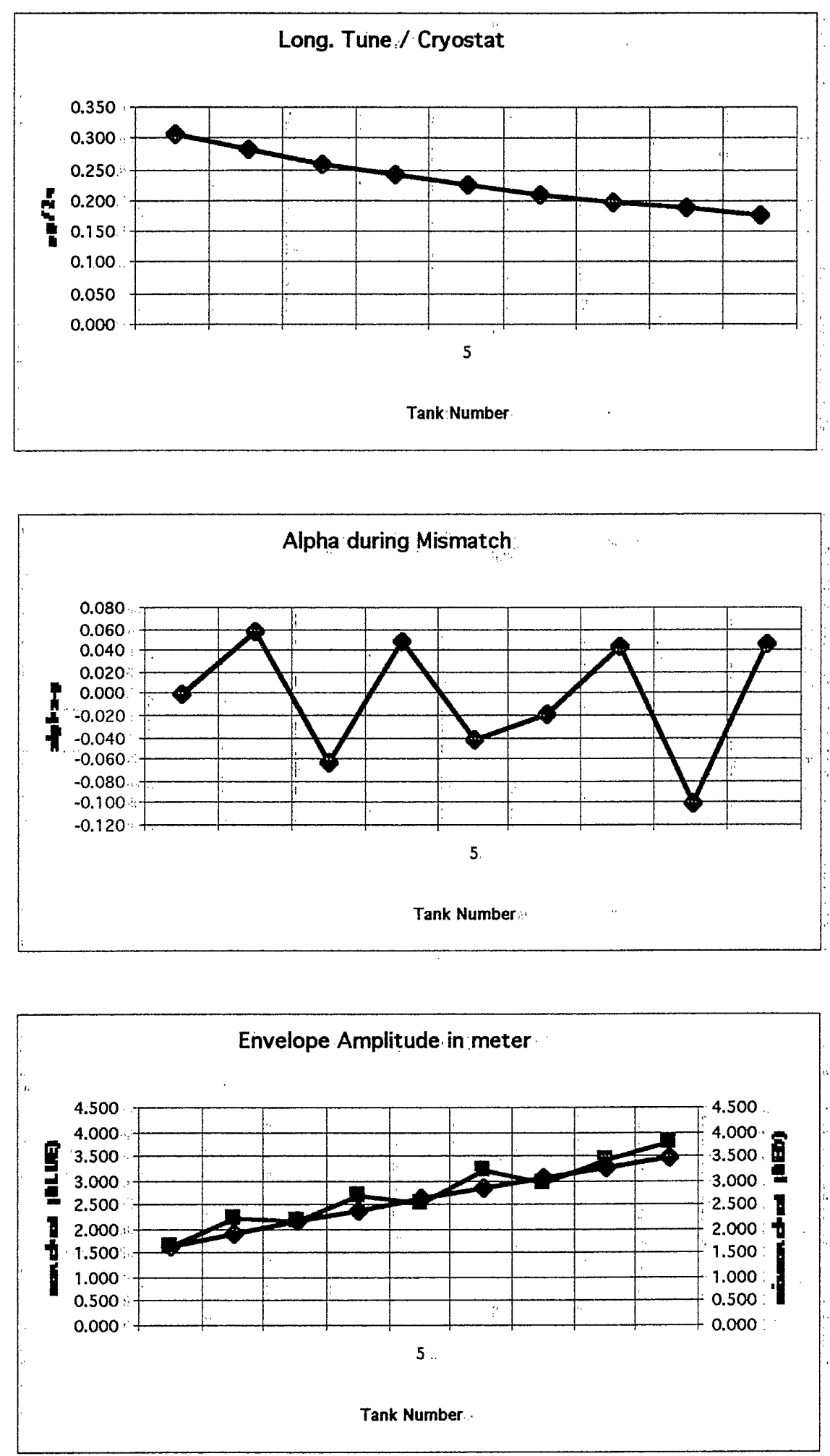

Figure 5. Plots (3) of Behavior vs: period (tank) number of LE Section. 

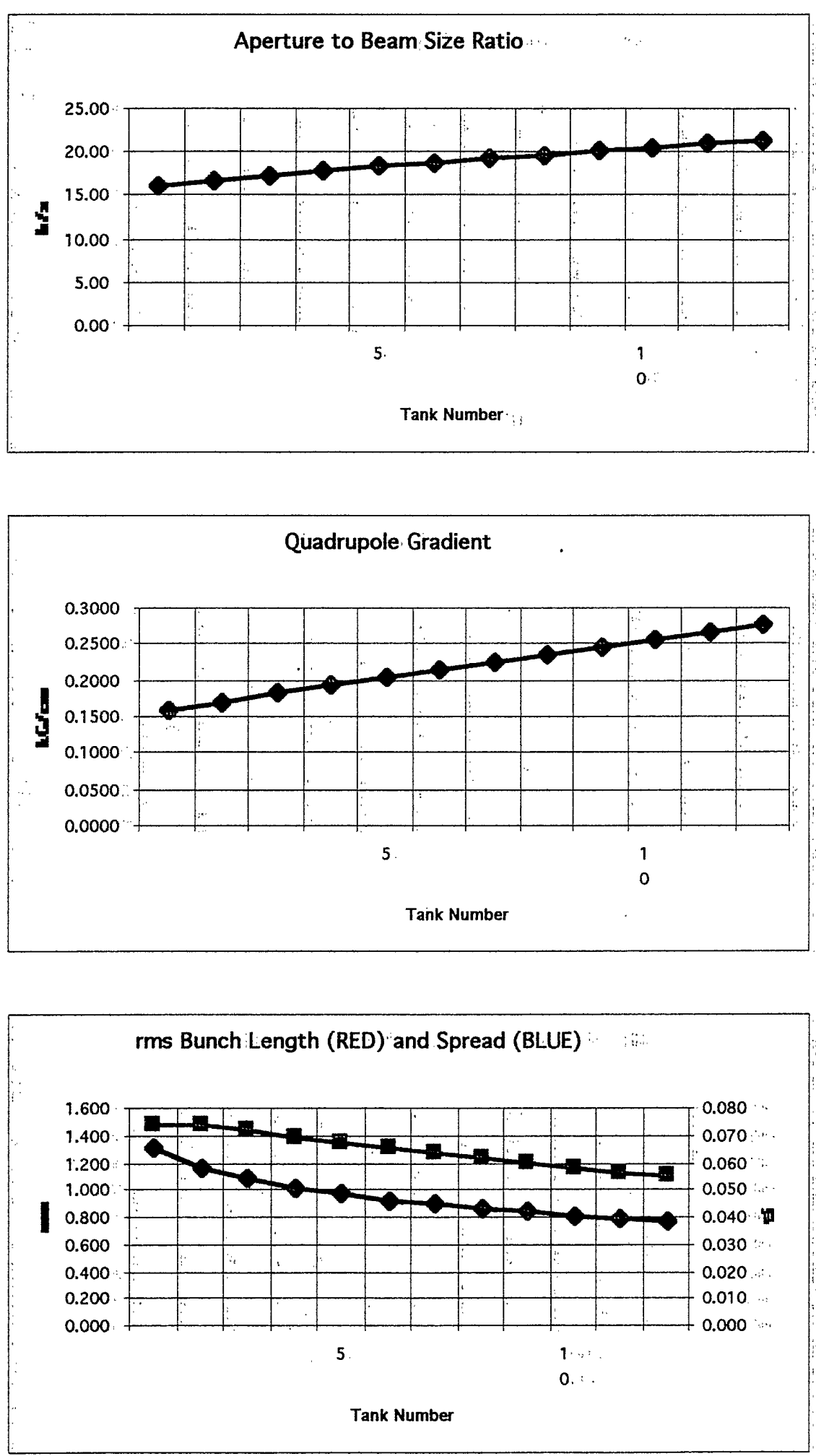

Figure 6. Plots (1) of Behavior vs: period (tank) number of MLE Section. 

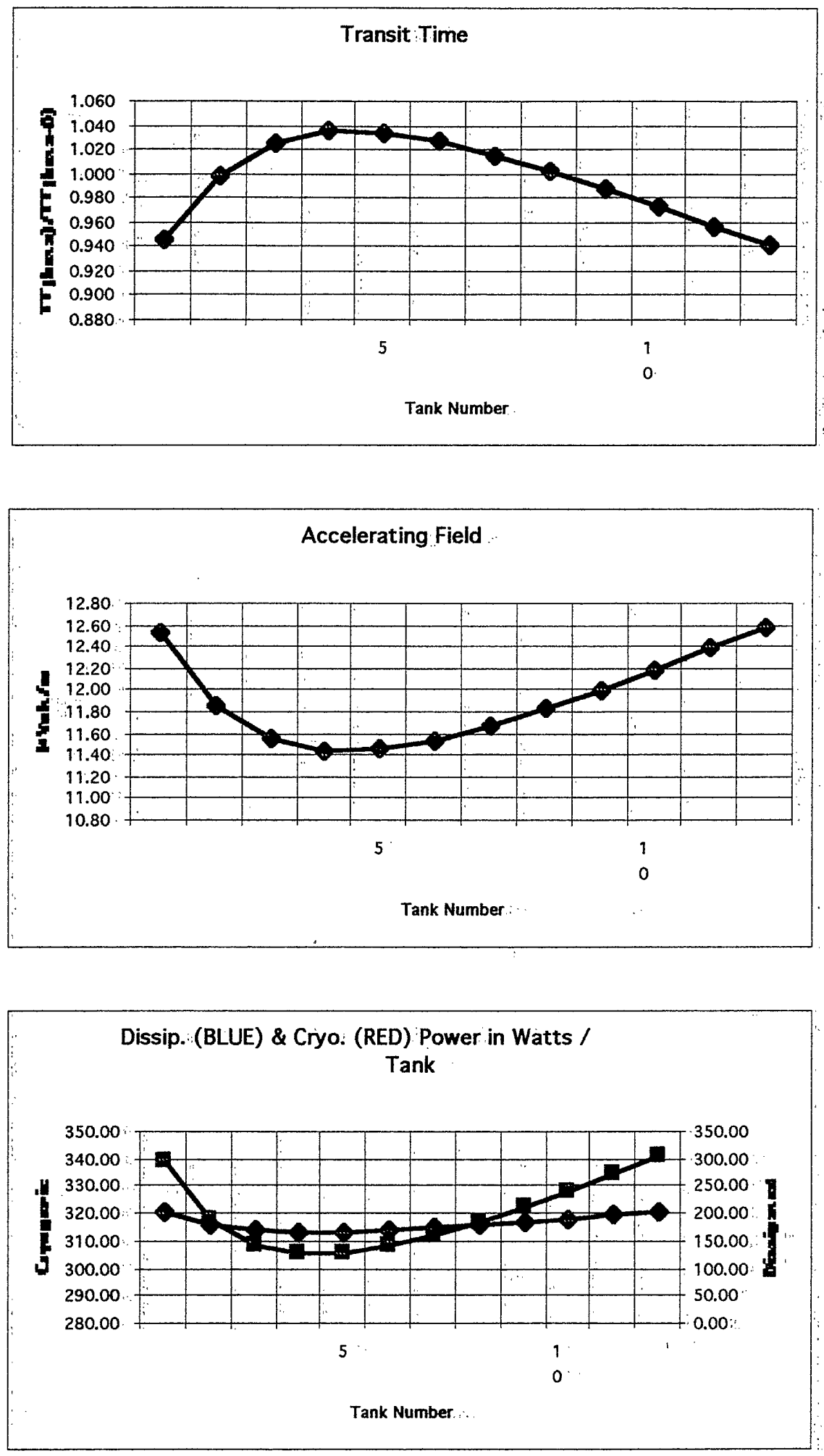

Figure 7. Plots (2) of Behavior vs. period (tank) number of MLE Section: 

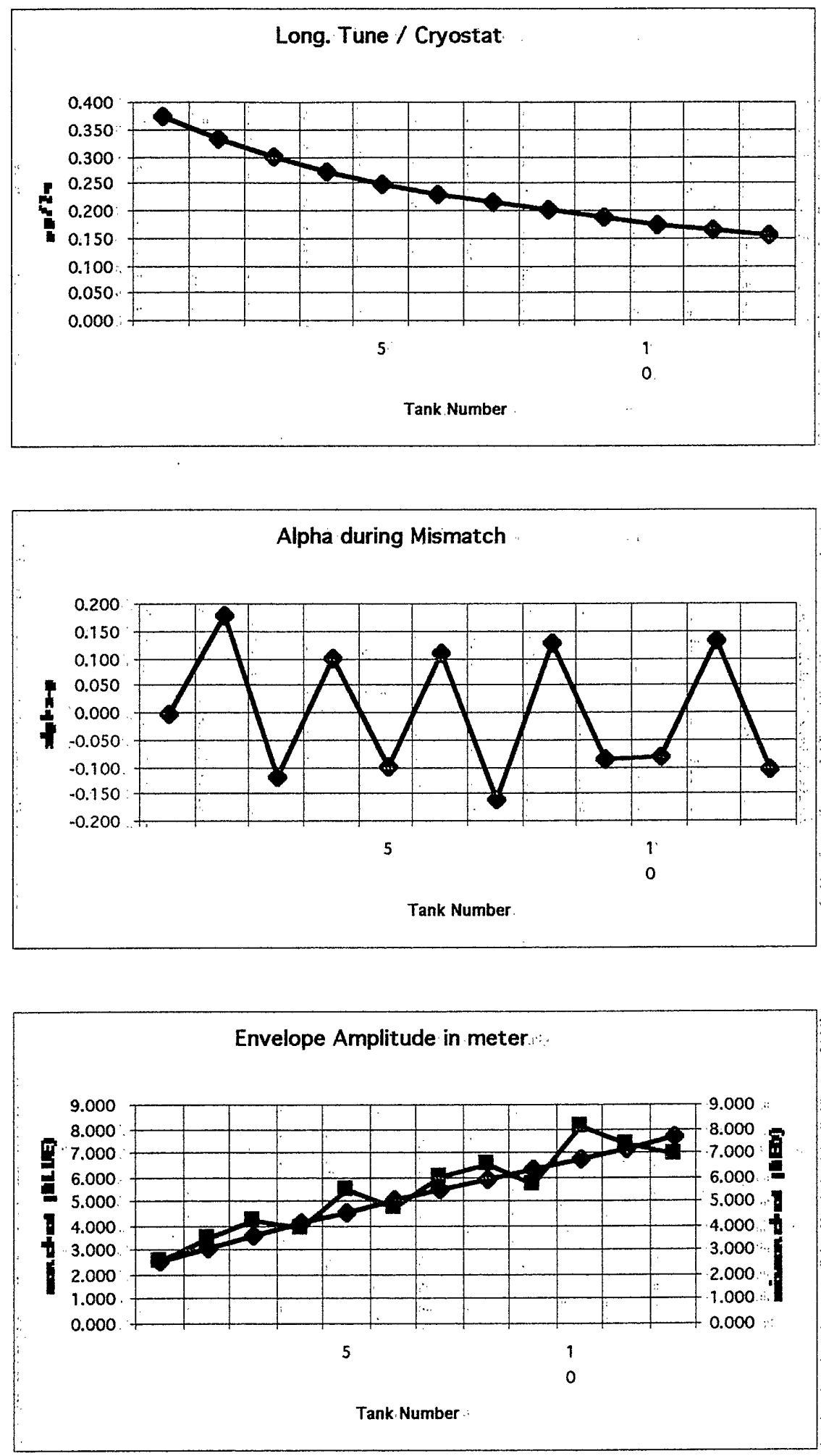

Figure 8. Plots (3) of Behavior vs: period:(tank) number of MLE Section: 

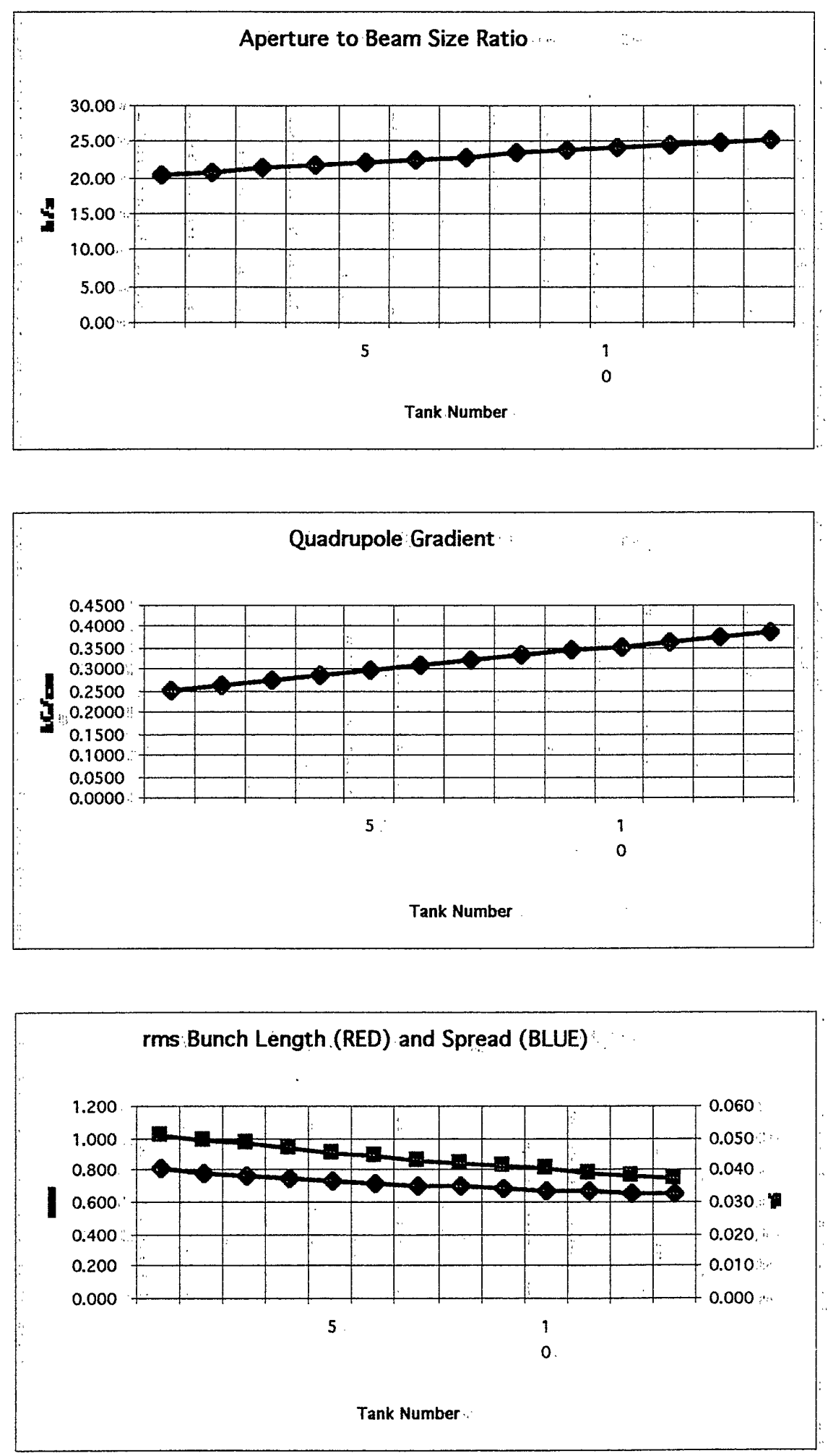

Figure 9. Plots (1) of Behavior vs. period (tank) number of MHE Section. 

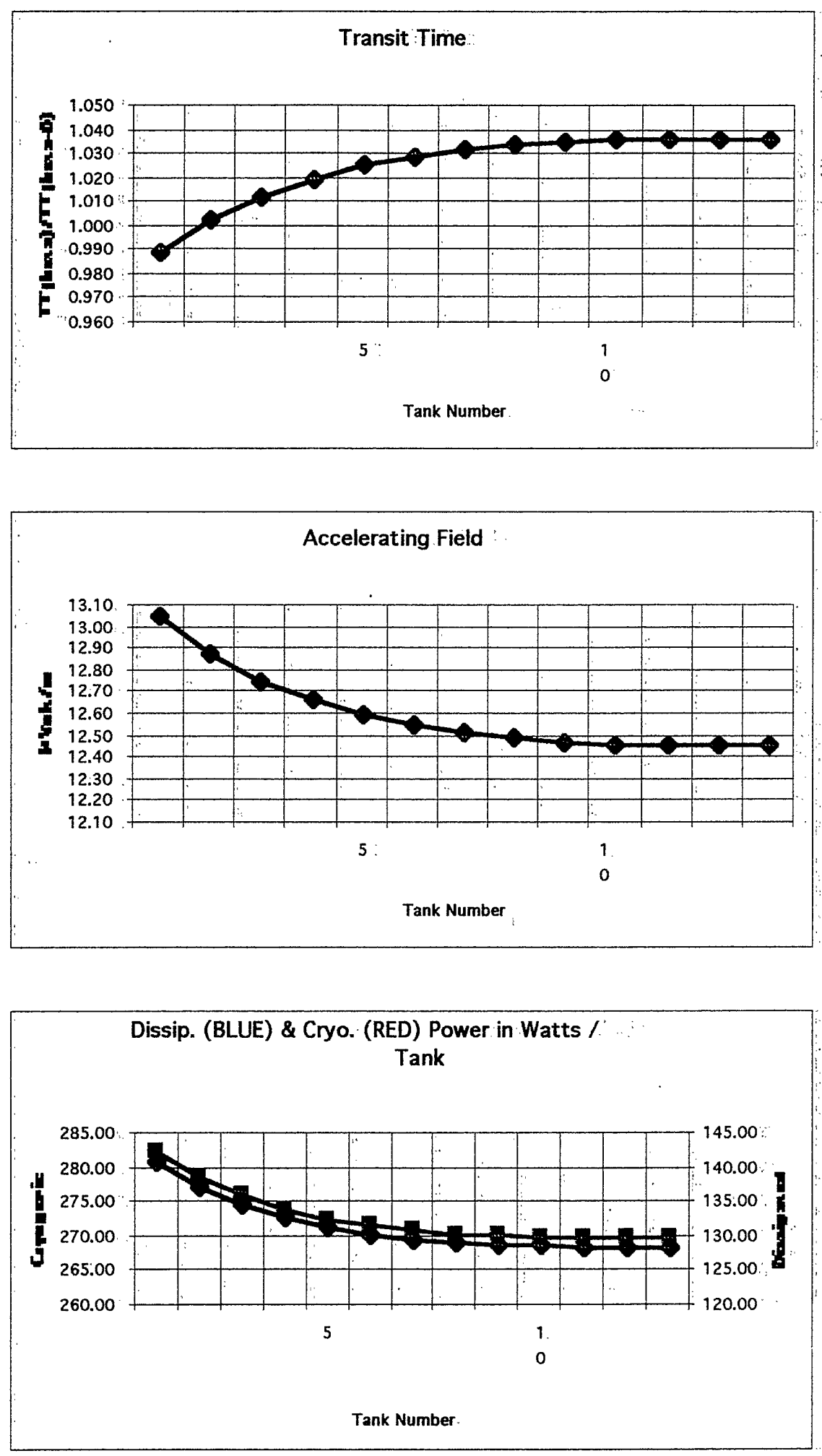

Figure 10. Plots (2) of Behavior vs. period.(tank) number of MHE Section. 

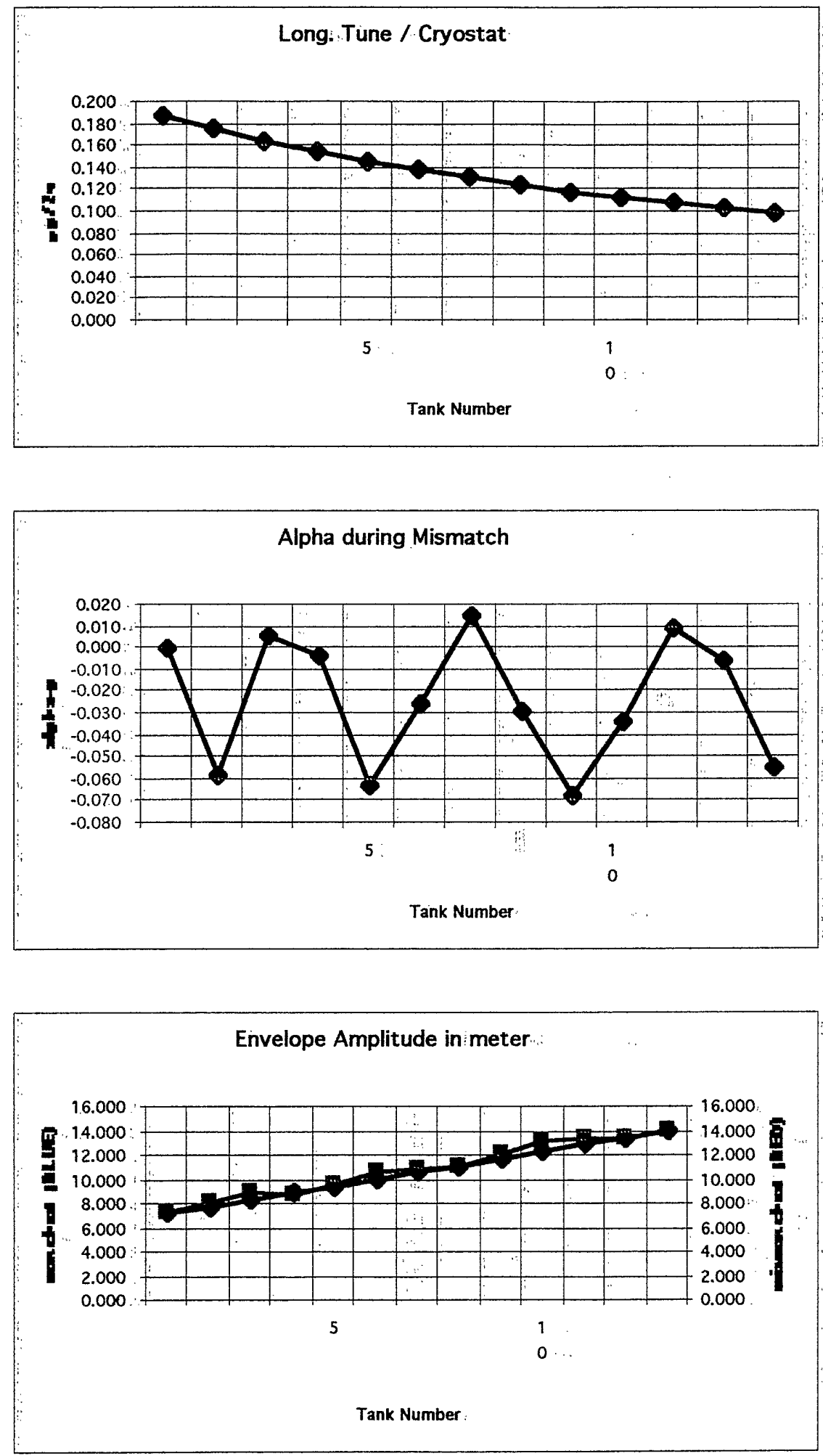

Figure 11. Plots (3) of Behavior vs. period (tank) number of MHE: Section. 

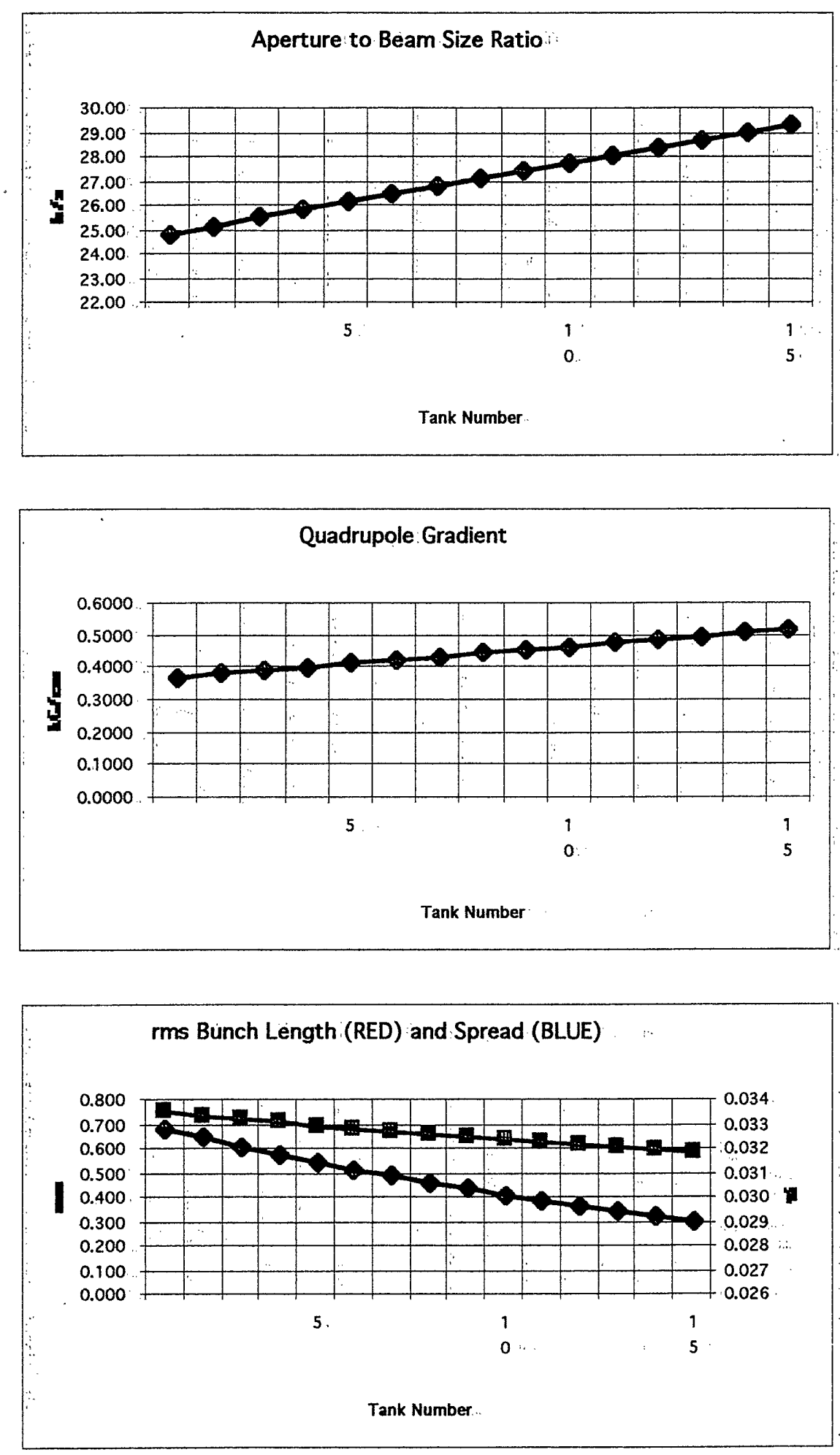

Figure 12. Plots (1) of Behavior vs. period (tank) number of HE Section. 

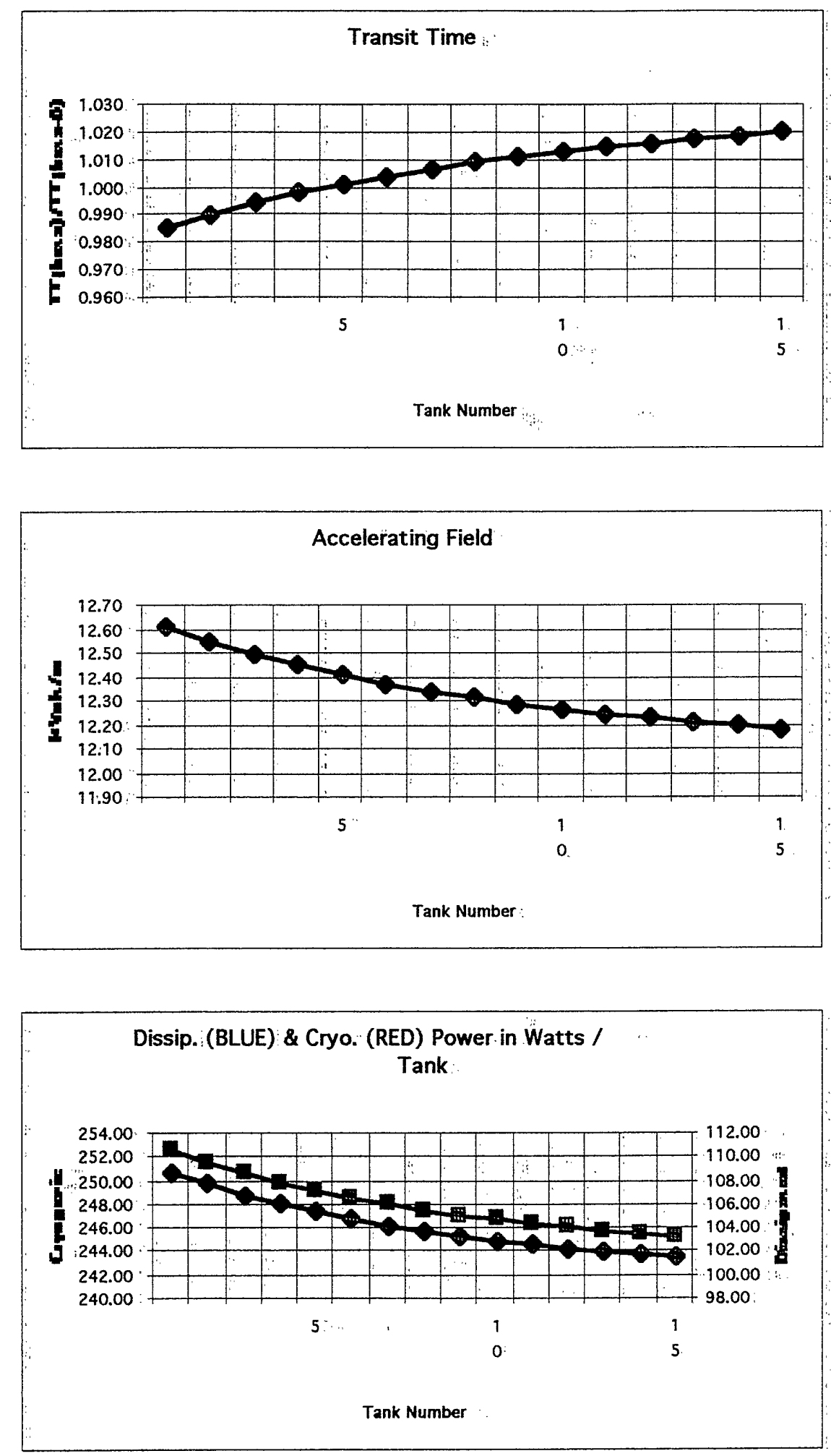

Figure 13. Plots (2) of Behavior vs. period (tank) number of HE Section. 

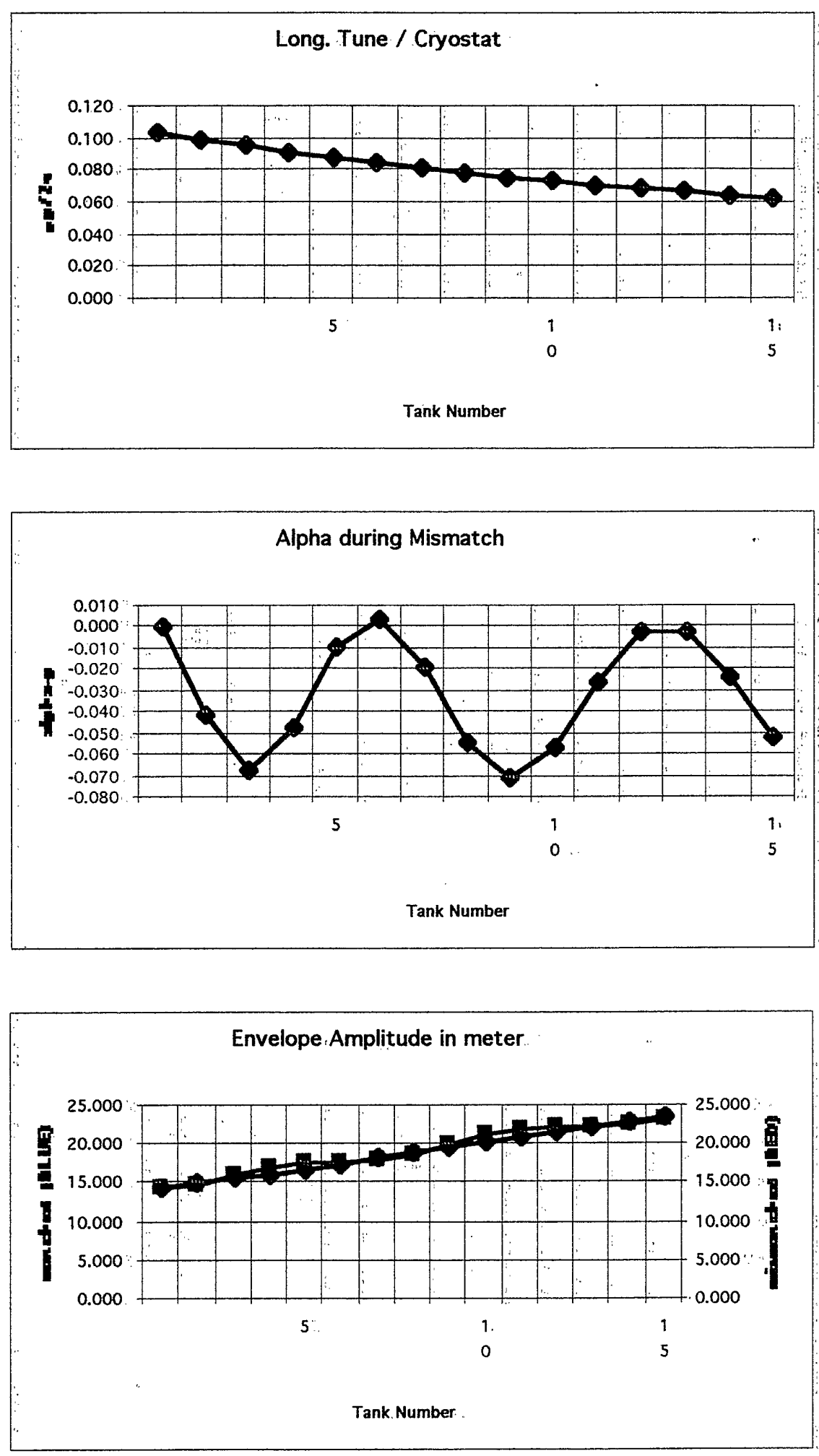

Figure 14. Plots (3) of Behavior vs. period (tank) number of HE Section. 